\title{
Three Stages of Evolution in the Treatment of Acute Ischemic Stroke: Stroke Unit Care, Intravenous Thrombolysis and Endovascular Therapy
}

\author{
J Chen ${ }^{1}$, SF Zhang ${ }^{1}$, ML Liu $^{1}$, and CC Ren ${ }^{* 1,2}$
}

${ }^{1}$ Department of Neurology, Shanghai the Fifth People's Hospital, Fudan University, Shanghai, China

${ }^{2}$ Department of Neurology, Shanghai East Hospital, Tongji University, Shanghai, China

*Corresponding author: CC Ren, Department of Neurology, Shanghai the Fifth People's Hospital, Fudan University, Shanghai, China, Department of Neurology, Shanghai East Hospital, Tongji University, 150 Jimo Road, Pudong New Area, Shanghai, China, E-mail: rccfns17@sina.com

Citation: J Chen, SF Zhang, ML Liu, CC Ren (2017) Three Stages of Evolution in the Treatment of Acute Ischemic Stroke: Stroke Unit Care, Intravenous Thrombolysis and Endovascular Therapy. J Neurol Neurol Disord 3(3): 304

Received Date: October 12, 2017 Accepted Date: December 14, 2017 Published Date: December 18, 2017

\begin{abstract}
Ischemic stroke is the most frequent cause of disability in adults in the world and its treatment remains a challenge. The care management of stroke patients in organized stroke units has improved and various revascularization approaches have emerged during the past decades. Stroke patients cared in organized stroke units are more likely to survive, to return home and to be functional independency. It is recommended that all patients with stroke, regardless of age, should be cared in a stroke unit. Intravenous thrombolysis with recombinant tissue plasminogen activator delivered within 4.5 hours after symptom onset is the only approved and effective medical therapy in patients of acute ischemic stroke. However, the narrow therapeutic window, contraindications and low recanalization rate of intravenous thrombolysis in proximal intracranial arterial occlusion result in consistently low utility rate among stroke patients. The endovascular therapy with or without intravenous thrombolysis has proved to achieve high rates of recanalization in a short period of time, without increased detrimental effects when intravenous thrombolysis is low efficacy in the location of terminal internal carotid artery, M1 or M2 portions of the middle cerebral artery. More researches evaluating the optimal timeframe, the effects among stroke patients with the posterior circulation or among elderly stroke patients, and the cost-effectiveness of adjunctive endovascular mechanical thrombectomy are expected before its widespread implementation in clinical. Presently, neurologists or neuroradiologists should make the best use of available resources to maximally benefit as many stroke patients as possible.
\end{abstract}

Keywords: Ischemic stroke; Stroke unit; Intravenous thrombolysis; Endovascular; Thrombectomy

\section{Introduction}

Stroke is a major public health-care challenge that is considered to be the second leading cause of death and the prime cause of acquired disability worldwide [1]. It is reported that almost 800,000 people are suffered with stroke every year in the United States, leading to 200,000 deaths, approximately every one of sixteen deaths [2]. In the developing countries, the situation is more serious [3]. In China, 2.5 million new stroke patients are reported each year, making stroke becoming the leading cause of adult death and disability [4]. For the survivors, the annual costs of stroke care are as high as 40 billion RMB in China, which, without doubt, placing a substantial health and economic burden on the society [5-7].

It is estimated that more than $80 \%$ of incident stroke are of ischemic type, due to an occlusion in a cerebral artery caused by a thrombus or thromboembolism [8]. Ischemic stroke is a continuous and dynamic process of infarct expansion that varies as elapse of the time, deprivation of blood flow and other factors [9]. The well-known term of "time is brain" underlines the rapidity of loss of neural structures during an ischemic stroke, which is reported, on average, to be 13.6 billion synapses, $11.9 \mathrm{~km}$ of neuronal fibers and 1.9 billion of neurons with each passing minute [10]. Therefore, timely recanalization in the occluded artery often makes for the salvage of ischemic penumbra, the restoration of cerebral perfusion and improvement of clinical outcomes [11].

The evolution of treatment for acute ischemic stroke (AIS) could be a long and complicated process. Before CT/MRI was applied to clinic, neutral treatments both for ischemic stroke and hemorrhage stroke became the treatment options for AIS. However, these treatments like hypervolemia treatment and anti-edema therapy were futile to lower mortality and morbidity as the existence of secondary vascular damage and complications related to AIS. Along with the development of imaging technology, specific 
treatments for AIS have been emerged during the past several decades. All the attempts of treatment in AIS aimed to reduce the mortality, lessen the dependency and minimize the complications caused by stroke; promote neurologic functional outcomes and improve health-related quality of life of stroke survivors; lower the risk of recurrence of AIS. Here, we propose that the evolution of treatment in AIS could be summarized to be three landmark emergences: organized stroke unit care, intravenous thrombolysis (IVT) and endovascular therapy (EVT), called AIS Therapy 1.0, AIS Therapy 2.0 and AIS Therapy 3.0, respectively. This article will review the development and progression of these three treatment options and discuss the implications for future comprehensive treatment in clinical for AIS with special emphasis on patient selection and treatment strategy.

\section{AIS Therapy 1.0: The Organized Stroke Unit Care Era Definition of Organized Stroke Care}

Stemming from 1950s, the term organized stroke unit care has been used to describe the focusing of care for stroke patients in hospital that is provided by a multidisciplinary team who specialize in stroke management, including neurologists, professional nurses, language trainers and physical therapists, and neural psychological doctor [12]. Stroke unit care is a centralized management mode for stroke patients and is capable to provide patients with drug therapy, language training, physical rehabilitation, psychological treatment and health education, aiming to reduce stroke-related mortality and morbidity, reduce the complications and the recurrence rate, improve patient's quality of life, the family member satisfaction, and improve patients awareness of risk factors for stroke prevention and effects $[13,14]$.

\section{Effects of Organized Stroke Care}

It has been reported that the short-term effects of stroke unit care include the lowered mortality, and shortened hospitalization stay [15]; the long-term effects refers to improving patients' independency, five-year survival rate and decreased the need for institutionalization [16-20]. A large randomized controlled trial (RCT, $\mathrm{n}=1241$ ) showed that stroke unit care significantly decreased patients' hospital stay, improved the survival rate of hospitalization period, survival rate of half-year and survival rate of one-year. Also, patients cared in stroke units were more likely to return home after discharge [15]. Further analysis of the study reported that five-year survival rate of the patients increased by $40 \%$ [16]. An observational study retrospectively examined 11572 acute stroke patients from 260 Italian hospitals [17]. Compared with care on a general ward $(n=6636)$, stroke unit care $(n=4936)$ was associated with a reduced likelihood of death or being disabled (Rankin score $>2$ ) at the end of two-year follow-up period (OR=0.81; $95 \% \mathrm{CI}$ : 0.72-0.91; $\mathrm{P}=0.0001)$. Similar conclusions were reported in studies.

A latest systematical review and meta-analysis identified 28 trials of 5855 patients and indicated that patients in stroke unit care are more apt to survive their stroke $(\mathrm{OR}=0.76$; 95\% CI: 0.66-0.88; $\mathrm{P}=0.0001)$, return home $(\mathrm{OR}=0.76$; 95\% CI: 0.67-0.86; $\mathrm{P}=0.0001)$ and have greater ability to take care of themselves (OR=0.74; 95\% CI: 0.61-0.90; $\mathrm{P}=0.002)$ [18-20]. Moreover, the potential beneficial effects of organized stroke unit care are independent on sex, age, time of admission or stroke severity [14]. Actually, the European Stroke Organization (ESO) recommends that all patients with stroke, regardless of age, should be cared in a stroke unit (class I, level A evidence) [21-23].

\section{Potential Mechanisms of Effects of Organized Stroke Care}

Several underlying mechanisms of short-term and long-term effects of stroke unit care have been implicated: patients receive rehabilitation training at the early stage after stroke [24]; closely relationship between patients and the multidisciplinary team of stroke unit care, and active participation of family members in the process of treatment have a positive psychology effects on patients, which, in turn, enhance patients' confidence and motivation [25]; weekly meetings among a multidisciplinary team to further understand patients' condition and disease change tend to lower the risk of complications [26]; stroke-related health education among patients and family members make for mobilize their subjective initiative [27].

\section{Management Items of Organized Stroke Care}

\section{Blood Pressure Control}

Due to elevated intracranial pressure, mental stress, injury to automatic control systems, or attenuated parasympathetic activity [28-30], as high as $80 \%$ of stroke patients' manifest arterial blood pressure above $140 / 90 \mathrm{mmHg}$ on admission [31-32]. Even though results of several trials indicated that decreasing blood pressure was not associated with more beneficial outcomes [3334 ], it is recommended that blood pressure should be carefully lowered when diastolic pressure $>110 \mathrm{mmHg}$ or systolic pressure $>220 \mathrm{mmHg}$ to acquire a conservative effect. For post-thrombolytic stroke patients, management of blood pressure should be more cautious as patients with post-thrombolytic symptomatic intracerebral hemorrhage (sICH) have significantly higher systolic blood pressure within $48 \mathrm{~h}$ after thrombolysis than patients without sICH [35].

\section{Glucose Control}

Numerous studies have documented the increased glucose level associated with poor outcomes at the acute stage [36-38]. A large investigational study which aimed to explore dynamics of glucose levels and the association of hyperglycemia with outcomes after thrombolysis among ischemic stroke patients demonstrated that glucose level $\geq 8.0 \mathrm{mmol} / \mathrm{l}$ within $48 \mathrm{~h}$ after intravenous 
thrombolysis is strongly associated with sICH and death [39]. On the other hand, strict glycemic control during the 3 months after stroke was not associated with decreased death or dependence (OR=.99; 95\% CI: 0.79-1.23), while a higher risk of symptomatic hypoglycemia among stroke patients was found (OR=14.6; 95\% CI:6.6-32.2) according to a systematical review and meta-analysis [40]. Still, blood glucose level is recommended to be less than $11 \mathrm{mmol} / \mathrm{L}$ [41].

\section{Temperature Control}

Hyperthermia is a frequent complication in patients with AIS. Moderate evidence for ESO suggests that it might be a means to elevate survival or improve functional outcomes in patients with AIS by using antipyretics to routine prevention of hyperthermia [42]. It is recommended to avoid temperature above $37.5^{\circ} \mathrm{C}$ [41].

\section{Antiplatelet Therapy}

Aspirin has long been established as the standard treatment for patients with AIS [43]. Data from a recently meta-analysis indicated that dual antiplatelet therapy (aspirin plus clopidogrel) was more likely to lower the risk of numerous vascular events, especially in the prevention of recurrence stroke or transient ischemic attack (TIA) compared with aspirin alone when administrated for a short time period, but when given for a long time period, the elevated bleeding risk outweighed the beneficial effects [44]. Hence, timeframe is crucial to administrated dual antiplatelet therapy. A study published in the New England Journal of Medicine demonstrated that dual antiplatelet therapy was superior to single-antiplatelet therapy (a dose of $75 \mathrm{mg}$ aspirin) when administrated for a timeframe of 90 days [45].

Number of studies compared the treatment effects of aspirin associated with clopidogrel (dual antiplatelet therapy, DAPT) with aspirin alone. In 2006, the study Clopidogrel and Aspirin versus Aspirin Alone for the Prevention of Atherothrombotic events (CHARISMA) further established the role of aspirin in the prevention and control of cardiovascular disease. Besides, the study reported that compared with aspirin, DAPT not only achieved no extra treatment effects $(\mathrm{OR}=0.93$; 95\% CI: 0.83-1.05; $\mathrm{P}=0.22)$, but also increased the risk of hemorrhage $(\mathrm{OR}=1.62 ; 95 \% \mathrm{CI}: 1.27-2.01$; $\mathrm{P}<0.0001)$. In 2012, the Secondary Prevention of Small Subcortical Strokes (SPS3) study was terminated early because DAPT (aspirin plus clopidogrel) bought higher risk of hemorrhage (5.5\% vs $2.5 \%)$ and all-cause mortality (5.8\% vs $4.1 \%)$ than aspirin alone [46]. However, in 2013, Wang et al. reported that for patients with high risk of TIA or acute minor stroke, the risk of early recurrence was reduced following treatment with DAPT which is taken within $24 \mathrm{~h}$ after symptom onset and taken for 3 months compared with aspirin alone, and the risk of massive bleeding did not increased [47]. In addition, RCTs weighting combination of dipyridamol plus aspirin over aspirin alone are needed before the addition of dipyridamol to aspirin in widely accepted for prevention of stroke [48].

\section{Lipid-Lowering Therapy}

Findings of a latest meta-analysis of observational study and randomized trials showed that statin (a lipid-lowering agent) used in hospitalization period was prone to improve functional outcomes $(\mathrm{OR}=1.31$; 95\% CI: $1.12-1.53, \mathrm{P}=0.001)$ and reduce mortality $(\mathrm{OR}=0.41$; 95\% CI: 0.59-0.58, $\mathrm{P}<0.001)$ [50]. However, current guidelines do not provide specific recommendations on statin initiation in AIS owing to the scarce of large RCTs.

\section{Mobilization}

There is no agreement about the optimal time point to start mobilization after stroke. It has been reported mobilization within 24 hours of stroke seems to be safe, could help to reduce complications associated with immobility, and place obvious psychological effects [52-56]. Nevertheless, some researchers suggest that it is critical to lie flat during the first 72 hours to maintain cerebral blood flow to the salvageable ischemic tissue [57]. Further researchers are needed to make clear guidelines on when to initiate mobilization after stroke [58].

\section{AIS Therapy 2.0: the Intravenous Thrombolysis Era}

\section{Establishment of Intravenous Thrombolysis for Patients with AIS}

Thrombolysis with intravenous administrated tissue plasminogen activator (IV t-PA) remains the only proven effective drug treatment for AIS [59], which was based on the landmark National Institute of Neurological Diseases and Stroke - II (NINDS- II ) trial of 333 stroke patients treated with IV t-PA within 3 hours of stroke onset published in 1995 [60]. It was randomized, placebocontrolled trial and showed that patients treated with IV t-PA $(0.9 \mathrm{mg} / \mathrm{kg})$ were $30 \%$ more likely to have minimal or no disability at 3-months outcomes. Even though the symptomatic intracranial hemorrhage (sICH) was $6.4 \%$, compared with $0.6 \%$ of placebo $(\mathrm{P}<0.001)$, no significant difference was found regarding mortality at 3 months between the groups. Earlier the same year, another randomized, placebo-controlled trial conducted by the European Cooperative Acute Stroke Study (ECASS-I) failed to found beneficial outcomes among 620 stroke patients treated with $1.1 \mathrm{mg} / \mathrm{kg}$ IV t-PA versus placebo within 6 hours of stroke onset [61]. In the next year, the Food and Drug Administration (FDA) approved the IV t-PA for the treatment of AIS within 3 hours after stroke onset. 


\section{Benefits and Time Window of IV t-PA}

In the following decades, studies were conducted to verify treatment effects of NINDS trial and to expand the 3-hour time window of IV t-PA. ECASS- II ( $\mathrm{n}=800$, 6-hour window), the Alteplase Thrombolysis for Acute Noninterventional Therapy in Ischemic Stroke (ATLANTIS) part A ( $\mathrm{n}=142$, 6-hour window) and part B ( $\mathrm{n}=613$, 5-hour window) reported no beneficial effects or early terminated due to harm [62-64]. A pooled analysis of 2775 patients included in NINDS ( I and II ), ECASS ( I and II ) and ATLANTIS (A and B) demonstrated that IV t-PA the OR for good outcome was greatest when the treatment was initiated within $90 \mathrm{~min}$ of symptom onset $(\mathrm{OR}=2.8 ; 95 \% \mathrm{CI}: 1.8-4.5)$, but benefit was remain found up to $270 \mathrm{~min}(0-90 \mathrm{~min}, \mathrm{OR}=2.8,95 \% \mathrm{CI}$ : 1.8-4.5; 91-180 $\mathrm{min}, \mathrm{OR}=1.55,95 \% \mathrm{CI}: 1.14-2.42 ; 181-270 \mathrm{~min}, \mathrm{OR}=1.4,95 \% \mathrm{CI}: 1.05-1.85$ ) [65]. The Safe Implementation of Thrombolysis in Stroke Monitoring Study (SITS MOST) investigated the safety of IV t-PA among 6483 stroke patients treated in the community. Data from this study showed $1.7 \%$ of 24 -hour sICH using the SITS MOST definition (parenchymal hematoma 2 with NIHSS $\geq 4$ or death), $7.3 \%$ of 7 -day sICH based on the Cochrane definition (hemorrhage with any neurological deterioration or death in 7 days), and $11.3 \%$ of mortality [66]. ECASS-was a randomized placebo-controlled trial in patients of AIS treated with IV t-PA during 3 to 4.5 hours after stroke onset [67], and showed a favorable clinical outcomes (OR=1.34; 95\% CI: 1.02-1.76; $\mathrm{P}=0.04$ ) and relatively low rate of sICH (IV t-PA versus placebo: $2.4 \%$ vs $0.2 \%$ ). Despite this, the FDA has not authorized IV t-PA for the extended time window. It is worth noting that, patients of potential high risk of sICH were excluded in this study, including patients over the age of 80 years, with NIHSS $\geq 25$, taking anticoagulants, with both diabetes and prior stroke, or imaging with over one third of the territory of the middle cerebral artery (MCA) involved. Echoplanar Imaging Thrombolytic Evaluation Trial (EPITHET) was another randomized controlled-placebo trial aimed to expand the time window up to 6 hours using diffusionweights imaging (DWI)/ perfusion-weights imaging (PWI) mismatch [68], in which 101 patients were randomized assigned to alteplase $(n=52)$ and placebo $(n=49)$. Results showed that alteplase was significantly associated with increased reperfusion $(\mathrm{P}=0.001)$, which was correlated with improved clinical outcomes, but not associated with attenuated infarction growth $(\mathrm{OR}=0.69$; 95\% CI: 0.38-1.28; $\mathrm{P}=0.239)$.

However, a post hoc case-control study, which pooled patients data from the EPITHET and the Diffusion and Perfusion Imaging Evaluation for Understanding Stroke Evolution Study (DEFUSE) showed that alteplase was significantly associated with lower infarct growth and increase reperfusion versus placebo in the time window of 3 to 6 hours in the patients with DWI-PWI mismatch $[69,70]$.

The Third International Stroke Trial (IST-3)-including 3035 patients randomized allocated to alteplase or placebo-was designed to examine to the benefits and harms among a wider range of patients (including the patients age over 80 years) of the treatment of IV t-PA within 6 hours after stroke onset [71]. The primary outcome was mortality or independency of enrolled patients at 6 months based on Oxford Handicap Score (OHS). IV t-PA showed no superior to placebo in 6-month independency (0† OHSt 2) and survival (adjusted $\mathrm{OR}=1.13 ; 95 \% \mathrm{CI}$ : $0.95-1.35 ; \mathrm{P}=0.181$ ), but was significantly associated with fatal or non-fatal sICH within 7 days (adjusted $\mathrm{OR}=6.94 ; 95 \% \mathrm{CI}$ : 4.07-11.8; $\mathrm{P}<0.0001$ ), or death within 7 days (adjusted $\mathrm{OR}=1.60 ; 95 \% \mathrm{CI}$ : 1.22-2.08; $\mathrm{P}=0.001$ ). A separate study, which followed up the participants of IST-3 for 18 months, showed that the difference of mortality at the end of follow-up between alteplase and placebo was insignificant $(\mathrm{P}=0.85)$, but the differences in the proportion of patients with OHS of 0-2 (adjusted $\mathrm{OR}=1.28 ; 95 \% \mathrm{CI}: 1.03-1.57 ; \mathrm{P}=0.024)$ and overall self-reported health based on the EuroQol instrument $(\mathrm{P}=0.019)$ were significantly [72]. Both of the trials reported a favorable shift in the distribution of OHS grades with adjusted common OR of 1.27 (95\% CI: $1.10-1.47 ; \mathrm{P}=0.001)$ at 6 months and 1.30 (95\% CI: 1.10-1.55; P=0.002) at 18 months [72].

A pooled analysis inclusive of patients from NINDS ( I and II ), ECASS ( I , II and III), ATLANTIS and EPITHET further reinforced the time-dependent benefits of IV t-PA up to 4.5 hours (0-90 $\mathrm{min}, \mathrm{OR}=2.55,95 \% \mathrm{CI}$ : $1.44-4.52$; $91-180 \mathrm{~min}, \mathrm{OR}=1.64$, 95\% CI: 1.12-2.40; 181-270 $\mathrm{min}, \mathrm{OR}=1.34,95 \%$ CI: 1.06-1.68) [73]. Conclusion of this study was in line with those of the previous two meta-analyses published in the year of 2004 and 2009, respectively [65,74], the later analyzed 1622 patients included only in ECASS I , II and III, and ATLANTIS. Although it is recommended the routine use of alteplase within 4.5 hours after stroke onset in patients of AIS in Europe, Australia and Japan [75-77], the FDA still approves the use of alteplase in the time window of only 3 hours [78]. A meta-analysis published in 2014 reviewed 27 randomized trials, involving 10187 patients either treated with any thrombolytic agents or placebo, to explore safety and efficacy of thrombolytic therapy [79]. Pooled analysis of individual trials exploring IV t-PA versus placebo showed a significant reduction in death or dependency with treatment up to 6 hours $(\mathrm{OR}=0.84$; 95\% CI; 0.77-0.93; $\mathrm{P}=0.0006$; 8 trials, 6729 participants ); treatment within 3 hours was more beneficial (OR=0.65; $95 \%$ CI: $0.54-$ $0.80 ; \mathrm{P}<0.0001 ; 6$ trials, 1779 participants). Once again, the time-dependent beneficial effects of IV t-PA administrated within 4.5 hours after stroke onset were further reinforced in a pre-specified meta-analysis of 6756 patient data from nine randomized [80].

\section{Complications of IV t-PA}

A lot of clinical trials have demonstrated IV t-PA was significantly associated with the increased rate of sICH. Results from a latest meta-analysis showed that alteplase significantly increased the odds of sICH versus placebo $(\mathrm{OR}=5.55$; 95\% CI: 4.01-7.70; $\mathrm{P}<0.0001$ ) [80]. Independent high risk factors of sICH include elderly patients, patients with hypertension, diabetes mellitus, high baseline NIHSS score, long onset and thrombolysis time, atrial fibrillation, low level of fibrinolytic enzyme inhibitors, or signs of early infarct demarcation on CT /MRI $[81,82]$. For stroke patients with atrial fibrillation, anticoagulation agents, such as Warfarin, should be taken $24 \mathrm{~h}$ after IV t-PA. 


\section{Limitations of IV t-PA}

The major limitation of IV t-PA is the narrow treatment time window, which has been considered to be the main cause of consistent low rate utilization of this therapy [83]. Survey showed that only 3\% to 7\% stroke patients were treated with IV t-PA [84,85]. Poor public awareness of stroke signs and symptoms, late hospital arrival of patients and limited facilities and access to acute neuroimaging make patients miss the time window [86]. Additionally, relatively low recanalization rates in patients with proximal vessels occlusions also restrict the use of IV t-PA. It has been showed that the recanalization rates in internal carotid artery (ICA), M1 or M2 segment of MCA and basilar artery (BA) are as low as 6\%, 30\%and 30\%, respectively [86-89]. Furthermore, the rates of timely recanalization in patients with initial severe stroke rated by NIHSS score and thrombus lengths over $8 \mathrm{~mm}$ are unsatisfying $[90,91]$.

\section{AIS Therapy 3.0: the Endovascular Therapy Era}

\section{Intra-artery Pharmacological Thrombolysis}

The evolution of EVT for AIS initiated with intra-artery pharmacological thrombolysis (IAT), effects of which were demonstrated in the Prolyse in Acute Cerebral Thromboembolism II (PROACT II) and the International Management of Stroke II(IMS II) trials [92,93]. The PROACT II randomly assigned 180 patients within 6 hours of onset of large MCA occlusion either to intra-arterial recombinant pro-urokinase ( $\mathrm{r}$-pro UK) or intra-venous heparin, and showed significantly increased rate of partial or complete recanalization (T1M1 2-3) $(\mathrm{P}<0.001)$ and improvement in functional outcomes (modified Rankin Score, mRS 2) $(\mathrm{P}=0.04)$ in the r-pro UK group at 90 days [92]. The IMS II , a single-arm, historical control study, examined the effects and safety of low dose intravenous t-PA $(0.6 \mathrm{mg} / \mathrm{kg})$ and intra-arterial t-PA (up to $22 \mathrm{mg}$ ) delivered via a microcatheter navigated by a microwire to the occlusion site among 81 patients within 3 hours from symptom onset. The rate of recanalization (T1M1 2-3) was $60 \%$ and the proportion of patients with mRS +2 at 90 days was 46\% in this study, which was 39\% in the NINDS IV t-PA group. Although high rate of sICH (9.9\%) was reported, it was low mortality at 90 days (16\%) [93]. Similar results were demonstrated in a meta-analysis involving 395 patients data from five individual trials published in Stroke in 2010 [94]. Local IAT appears to provide an economical approach when the occlusion happens in distal artery, endovascular access is difficult, or the diameter of the vertebral or carotid artery is short, but the therapy has been widely substituted by the mechanical retrieval of thromboembolus due to long recanalization time, high rate of sICH and low rate of recanalization in proximal vessels [95].

\section{Mechanical Thromboectomy Devices}

As the first generation mechanical retriever devices, the MERCI retriever (Stryker Neurovascular, Mountain View, CA, USA) and Penumbra Stroke System (Penumbra, Alameda, CA, USA) were approved by the FDA for mechanical thrombectomy within 8 hours after stroke onset in 2004 and 2007. The FDA's decision was based on the high rate of recanalization in large vessels occlusion of AIS using these devices rather than on the efficacy in improving functional outcomes. The Mechanical Embolus Removal in Cerebral Ischemia (MERCI) and multi-MERCI studies, which assessed the safety and efficacy of the MERCI device [96,97], showed a revascularization rate of $48 \%$ and $55 \%$ after thrombectomy alone; this increased to $60 \%$ and $68 \%$ with the use of adjunctive intraarterial thrombolytics, respectively. The Penumbra System utilizes mechanical clot separators coupled with aspiration from a reperfusion catheter and works proximally to the thrombus versus the MERCI devices [98]. The Penumbra Stroke Trial-designed to examine the safety and efficacy of the Penumbra System-reported recanalization and good clinical outcomes (mRSt 2) were obtained in $82 \%$ and $25 \%$ of all the patients [99]. However, no significant difference in the rate of favorable clinical outcome was identified compared to the PROACT II control arm. The delayed time of treatment of the patients may be the cause of the disappointing improvement in functional outcome.

\section{Mechanical Stent Retrievers Devices}

Two stent retrievers devices, Solitare (Covidien/ev3, Dublin, Ireland) and Trevo (Stryker Neurovascular, Mountain View, CA, USA), were approved by the FDA in 2012 for treatment of AIS caused by large vessel occlusions (LVO). Solitare and Trevo are superior to the first generation mechanical devices for two reasons: first, they can entrap and displace thrombus against the vessels wall, allowing immediate restoration of blood flow without the clot removed; additionally, these devices engage the thrombotic material in multiple sites, even in small peripheral vessel branches [100]. Two multicenter prospective RCTs comparing Solitare and Merci (the Solitaire with Intention for Thrombectomy, SWIFT study) and comparing Trevo and Merci (Trevo-2 study) have showed superiority to the Merci retriever devices [101,102]. In SWIFT study, both recanalization rates of TIMI 2 or greater $(89 \%$ versus 67\%) and 3-month functional outcomes assessed by mRS 0-2 (36\% versus 29\%) were better in the Solitaire group compared to the control group [101]. Similar results were acquired in Trevo-2 trial (reperfusion rate of 86\% versus 60\%; 3-month clinical outcomes of $40 \%$ versus 22\%) [102]. Because of the advantages of higher arterial recanalization rate and shorter procedure times, stent retriever devices have become the mainstream.

\section{Negative Results of Randomized Controlled Trials}

In 2013, three RCTs comparing EVT with or without IV t-PA versus IV t-PA for AIS failed to show any beneficial functional 
outcomes. These trials are the International Management of Stroke III (IMS- III) [103], the Mechanical Retrieval and Recanalization of Stroke Clots Using Embolectomy (MR RESCUE) and the Synthesis Expansion: A Randomized controlled Trial on Intra-Arterial Versus Intra-venous Thrombolysis in Acute Ischemic Stroke (SYNTHSIS Expansion) studies [104-105]. The IMS III study compared IV t-PA alone with combined IV t-PA and EVT, either IAT or mechanical endovascular techniques approved by the FDA. The study was early terminated after inclusion of 656 within 3 hours after symptom onset of an intended 900 patients owing to nonsignificant difference of preliminary results at 3 months (mRS 0-2 in 40.8\% in EVT group versus $38.7 \%$ in the IV t-PA group, $\mathrm{P}=0.25$ ) [103]. The MR RESCUE trial comparing standard medical care with EVT using Merci or Penumbra devices included 118 patients within 8 hours after stroke onset, 69\% (TICI 2a 3) of which achieved recanalization. No difference was identified in mean score of mRS between two groups (3.9 versus 3.9; $\mathrm{P}=0.99$ ) [104]. In the SYNTHSIS Expansion trial, 362 patients within 4.5 hours after the onset of stroke randomly assigned IV t-PA group or EVT group (mechanical clot disruption or retriever, IAT, or a combination). This study remains the only one which, up to now, compared the IV t-PA alone with EVT alone. The proportion of disability-free survival at 3 months (mRS of 01$)$ were similar between two groups $(30.4 \%$ in EVT group versus $34.8 \%$ in IV t-PA group, $\mathrm{P}=0.16)$. The occurrence rates of $\mathrm{sICH}$ were $6 \%$ in both groups $(\mathrm{P}=0.99)$. No effectiveness were found in these three studies partly due to the limitations of the trials: delayed initiation of treatment, no requirement on the presence of LVO (only the IMS-III study selected patients based on the CT angiographic evidence), the majority of patients treated by EVT using the first-generation mechanical retriever devices, and constantly changes in stroke care owing to long duration of patients inclusion [105-108].

\section{Positive Results of Randomized Controlled Trials}

In 2015, five published trials and two conference proceeding articles, assessing the safety and efficacy of the EVT without or with IV t-PA comparing with IV t-PA, presented positive results and revolutionized the endovascular therapy. They are the Endovascular treatment for acute ischemic stroke in the Netherlands (MR CLEAN) [109], the Endovascular Treatment for Small Core and Proximal Occlusion Ischemic Stroke (ESCAPE) [110], the Extending the Time for Thrombolysis in Emergency Neurological Deficits-Intra-Arterial (EXTEND-IA) [111], Solitaire With the Intention For Thrombectomy as PRIMary Endovascular Treatment (SWIFT-PRIME) [112], the Endovascular Revascularization With Solitaire Device Versus Best Medical Therapy in Anterior Circulation Stroke Within 8 Hours (REVASCAT) [113], and the Assess the Penumbra System in the Treatment of Acute Stroke (THERAPY) and the Trial and Cost Effectiveness Evaluation of Intra-arterial Thrombectomy in Acute Ischemic Stroke (THRACE) $[114,115]$. These trials are multicenter RCTs and have several characteristics in common on the design methods: radiological confirmation of LVO based on CTA or MRA; 3-months clinical outcomes assessed by mRS 0-2; only focus on occlusion involving the anterior circulation (the THRACE trial also included patients with occlusion in the posterior circulation); high rate of stent retriever devices use (more than $86 \%$ of overall average use rate among these seven trials). Subgroups analysis of a latest metaanalysis of these seven RCTs, comparing EVT versus medical care (IV t-PA) alone for AIS, showed the pooled risk ratio for these seven trials was 1.56 , with $95 \%$ CI 1.38 to 1.75 for the proportion of patients with $\mathrm{mRS} 0-2$ at 3 months $(\mathrm{P}<0.001)$, without increased mortality at 3 months $(\mathrm{P}=0.16)[116]$.

In general, results and recommendations from four published systematic reviews of RCTs evaluating the efficacy and safety of EVT for AIS consistently demonstrated that EVT, especially thrombectomy using stent retrievers, as an adjunctive treatment to IV t-PA is associated with the increased likelihood of favourable functional outcomes at 3 months after AIS caused by occlusion of anterior large vessels, without increased adverse impacts versus IV t-PA alone [116-119].

\section{Complications of EVT}

The rate of sICH of EVT with or without IV t-PA is equivalent to IV t-PA alone [120]. However, the risk of procedure-related complications is of particular concern in mechanical thrombectomy, mainly including hemorrhage, perforation of artery, rapture of vessel wall and contrast media extravasation [121,122]. In addition, attentions should be paid to the risk of embolic complications, which could affect the blood supply to the infarction area, reduce the salvable brain tissue, and result in additional ischemic lesions [123].

\section{Limitations of EVT}

Endovascular therapy appears to have expanded the therapeutic window up to 6 hours after stroke onset for stroke patients with LVO in the anterior circulation according to recent recommendations (class I a, lever A evidence) [124,125]. Nevertheless, the efficacy and safety of EVT among stroke patients caused by occlusion in posterior circulation remain uncertain due to the lack of RCTs regarding basilar artery occlusion (BAO). The Basilar Artery International Cooperation Study (BASICS) registry, evaluating one-month functional outcomes after treatment of EVT, IV t-PA or antithrombotic therapy alone, showed that outcomes are similar in patients with mild or moderate deficits among three groups, but severity patients treated with EVT or IV t-PA gained significant benefits comparing to those treated by conservative therapy alone, and no significant difference was identified between EVT and IV t-PA [126]. More RCTs are needed to examine the effects of EVT among patients with BAO [127]. Additionally, the implementation of EVT necessitates a patient-centred multidisciplinary organization in which all those involved (neurologists, diagnostic and interventional neuroradiologists, anesthetists) are available and can take immediate action [128]. 


\section{Conclusion}

The treatment of acute ischemic stroke has been the subject of numerous researches during the past several decades consisting of diverse care managements, medical and surgical approaches. Organized stroke unit care, intravenous thrombolysis with tissue plasminogen activator and endovascular mechanical thrombectomy have been confirmed to be highly effective therapies of AIS up to date. If conditions permit, all the stroke patients, regarding of age, sex, severity of stroke and time of admission should be cared in an organized stroke unit. One of main challenges of reperfusion therapies is how to safely extend the therapeutic window and allow as many patients as possible to benefit from the therapies. Approaches to shorten the treatment time of intravenous thrombolysis can also be implemented in endovascular treatments. It is crucial to improve of patient selection for intravenous thrombolysis or endovascular therapy. Endovascular mechanical thrombectomy and recanalization strategies are only effective and rapid when conducted in stroke patients with proximal large vessels occlusion, where intravenous thrombolysis is less effective. They can be applied as an adjunctive to the intravenous thrombolysis to increase the likelihood of revascularization. Studies investigating the optimal time window, the effects among stroke patients with the posterior circulation occlusion or old populations, and costs of adjunctive endovascular mechanical thrombectomy are anticipated before its application to clinical treatment. Currently, it is not only an exciting time, but also a critical moment for neurologists or neuroradiologists to make comprehensive consideration and cautious determinate what acute ischemic stroke intervention is the best option for individual patients of acute stroke to slow the ischemic cascade and improve clinical functional outcomes.

\section{Acknowledgement}

\section{C.C. Ren is supported by the Natural Science Foundation of China [Research Grants 81571277].}

\section{References}

1. Lozano R, Naghavi M, Foreman K, Lim S, Shibuya K, et al. (2012) Global and regional mortality from 235 causes of death for 20 age groups in 1990 and 2010 : a systematic analysis for the Global Burden of Disease Study 2010. Lancet 380: 2095-128.

2. O'Collins VE, Macleod MR, Donnan GA, Horky LL, van der Worp BH, et al. (2006) 1026 experimental treatments in acute stroke. Ann Neurol 59: 467-77.

3. Blackham KA, Meyers PM, Abruzzo TA, et al. (2012) Endovascular therapy of acute ischemic stroke: report of the Standards of Practice Committee of the Society of NeuroInterventional Surgery. J Neurointerv Surg 4: 87-93.

4. Langhorne P, de Villiers L, Pandian JD (2012) Applicability of stroke-unit care to low-income and middle-income countries. Lancet Neurol 11: 341-8.

5. Yang G, Wang Y, Zeng Y, Gao GF, Liang X, et al. (2013) Rapid health transition in China, 1990-2010: findings from the Global Burden of Disease Study 2010. Lancet 381: 1987-2015.

6. Tsai CF, Thomas B, Sudlow CL (2013) Epidemiology of stroke and its subtypes in Chinese vs white populations: a systematic review. Neurology 81:264-72.

7. Liu L, Wang D, Wong KS, Wang Y (2011) Stroke and stroke care in China: huge burden, significant workload, and a national priority. Stroke 42: 3651-4.

8. Roger VL, Go AS, Lloyd-Jones DM, Adams RJ, Berry JD, et al. (2011) Heart disease and stroke statistics-2011 update: a report from the American Heart Association. Circulation 123: e18-209.

9. Emberson J, Lees KR, Lyden P, Blackwell L, Albers G, et al. (2014) Stroke Thrombolysis Trialists' Collaborative Group. Effect of treatment delay, age, and stroke severity on the effects of intravenous thrombolysis with alteplase for acute ischaemic stroke: a meta-analysis of individual patient data from randomised trials. Lancet 384: 1929-35.

10. Saver JL (2006) Time is brain-quantified. Stroke 37: 263-6.

11. Rha JH, Saver JL (2007) The impact of re-canalization on ischemic stroke outcome: a meta-analysis. Stroke 38: 967-73.

12. Garraway M (1985) Stroke rehabilitation units: concepts, evaluation, and unresolved issues. Stroke 16: 178-81.

13. Tamm A, Siddiqui M, Shuaib A, Butcher K, Jassal R, et al. (2014) Impact of stroke care unit on patient outcomes in a community hospital. Stroke 45: 211-16.

14. Stroke Unit Trialists' Collaboration (2013) Organised inpatient (stroke unit) care for stroke. Cochrane Database Syst Rev 9: D197.

15. Jørgensen HS, Nakayama H, Raaschou HO, Larsen K, Hübbe P, et al. (1995) The effect of a stroke unit: reductions in mortality, discharge rate to nursing home, length of hospital stay, and cost. A community-based study. Stroke 26: 1178-82.

16. Jorgensen HS, Kammersgaard LP, Houth J, et al. (2000) Who benefits from treatment and rehabilitation in a stroke Unit? A community-based study. Stroke 31: 434-39.

17. Candelise L, Gattinoni M, Bersano A, Micieli G, Sterzi R, et al. (2007) Stroke-unit care for acute stroke patients: an observational follow-up study. Lancet 369: 299-305.

18. Berlit P, Popescu O, Klötzsch C, Diehl RR, Berg-Dammer E (1997) Treatment of acute stroke on the stroke unit. Initial experiences with an acute stroke unit in Germany. Der Nervenarzt 68: 122-8.

19. Fagerberg B, Claesson L, Gosmanhedström G, Blomstrand C (2000) Effect of acute stroke unit care integrated with care continuum versus conventional treatment: A randomized 1-year study of elderly patients: the Goteborg 70+ Stroke Study. Stroke 31: 2578-84.

20. Krespi Y, Gurol ME, Coban O, Tuncay R, Bahar S (2003) Stroke unit versus neurology ward--a before and after study. J Neurol 250: 1363-9.

21. Langhorne P, Williams BO, Gilchrist W, Howie K (1993) Do stroke units save lives? Lancet 342: 395-8.

22. Kaste M, Palomaki H, Sarna S (1995) Where and how should elderly stroke patients be treated? A randomized trial. Stroke 26: 249-53.

23. European Stroke Organisation (ESO) executive Committee; ESO writing Committee (2008) Guidelines for management of ischaemic stroke and transient ischaemic attack. Cerebrovasc Dis 25: 457-507.

24. Article T (1997) How Do Stroke Units Improve Patient Outcomes? A Collaborative Systematic Review of the Randomized Trials. Stroke 28: $2139-44$.

25. Lincoln NB, Blackburn M, Ellis S, Jackson J, Edmans JA, et al. (1989) An investigation of factors affecting progress of patients on a stroke unit. J Neurol Neurosurg Psychiatry 52: 493-96. 
26. Pound P, Sabin C, Ebrahim S (1999) Observing the process of care: a stroke unit, elderly care unit and general medical ward compared. Age Ageing 28: 433-40. 27. Smith J, Forster A, Young J (2004) A randomized trial to evaluate an education programme for patients and carers after stroke. Clin Rehabil 18: 726-36. 28. Wallace JD, Levy LL (1981) Blood pressure after stroke. JAMA 246: 2177-80.

29. Kannel W B, Wolf P A, Verter J, McNamara PM (1996) Epidemiologic Assessment of the Role of Blood Pressure in Stroke: The Framingham Study. JAMA 276: $1269-78$.

30. Willmot M, Leonardi-Bee J, Bath PM (2004) High blood pressure in acute stroke and subsequent outcome: a systematic review. Hypertension 43: 18-24.

31. Webb AJ, Fischer U, Mehta Z, Rothwell PM (2010) Effects of antihypertensive-drug class on interindividual variation in blood pressure and risk of stroke: a systematic review and meta-analysis. Lancet 375: 906-15.

32. SPS3 Study Group, Benavente OR, Coffey CS, Conwit R, Hart RG, et al. (2013) Blood-pressure targets in patients with recent lacunar stroke: the SPS3 randomised trial. Lancet 382: 507-15.

33. He J, Zhang Y, Xu T, Zhao Q, Wang D, et al. (2014) Effects of immediate blood pressure reduction on death and major disability in patients with acute ischemic stroke: the CATIS randomized clinical trial. JAMA 311: 479-89.

34. Sandset EC, Bath PM, Boysen G, Jatuzis D, Kõrv J, et al. (2011) The angiotensin-receptor blocker candesartan for treatment of acute stroke (SCAST): a randomised, placebo-controlled, double-blind trial. Lancet 377: 741-50.

35. Waltimo T, Haapaniemi E, Surakka IL, Melkas S, Sairanen T, et al. (2016) Post-thrombolytic blood pressure and symptomatic intracerebral hemorrhage. Eur J Neurol 23: 1757-62.

36. Bruno A1, Biller J, Adams HP Jr, Clarke WR, Woolson RF, et al. (1999) Acute blood glucose level and outcome from ischemic stroke. Trial of ORG 10172 in Acute Stroke Treatment (TOAST) Investigators. Neurology 52: 280.

37. Quinn TJ, Dawson J, Walters MR (2011) Sugar and stroke: cerebrovascular disease and blood glucose control. Cardiovascular Therapeutics 29: 31-42.

38. Ashburner JM, Go AS, Chang Y, Fang MC, Fredman L, et al. (2016) Effect of Diabetes and Glycemic Control on Ischemic Stroke Risk in AF Patients: ATRIA Study. J Am Coll Cardiol 67: 239-47.

39. Putaala J1, Sairanen T, Meretoja A, Lindsberg PJ, Tiainen M, et al. (2011) Post-thrombolytic hyperglycemia and 3-month outcome in acute ischemic stroke. Cerebrovasc Dis 31: 83-92.

40. Bellolio MF, Gilmore RM, Stead LG (2014) Insulin for glycaemic control in acute ischaemic stroke. Cochrane Database Syst Rev 1: CD005346.

41. European Stroke Organisation (ESO) Executive Committee, ESO Writing Committee (2008) Guidelines for management of ischaemic stroke and transient ischaemic attack. Cerebrovasc Dis 25: 457-507.

42. Ntaios G, Dziedzic T, Michel P, Papavasileiou V, Petersson J, et al. (2015) European Stroke Organisation (ESO) guidelines for the management of temperature in patients with acute ischemic stroke. Int J Stroke 10: 941-9.

43. No author (1997) CAST: randomised placebo-controlled trial of early aspirin use in 20,000 patients with acute ischaemic stroke. CAST (Chinese Acute Stroke Trial) Collaborative Group. Lancet 349: 1641-49.

44. Zhang Q, Wang C, Zheng M, Li Y, Li J, et al. (2015) Aspirin plus clopidogrel as secondary prevention after stroke or transient ischemic attack: a systematic review and meta-analysis. Cerebrovasc Dis 39: 13-22.

45. Wang Y, Wang Y, Zhao X, Liu L, Wang D, et al. (2013) Clopidogrel with aspirin in acute minor stroke or transient ischemic attack. N Engl J Med 369: 11-9.

46. Pfeffer MA, Jarcho JA (2006) The charisma of subgroups and the subgroups of CHARISMA. N Engl J Med 354: $1744-6$.

47. Benavente OR, White CL, Pearce L, Pergola P, Roldan A, et al. (2011) The Secondary Prevention of Small Subcortical Strokes (SPS3) study. Int J Stroke 6: 164-75. 48. Huang DY, Eisert WG (2013) CHANCE trial: early short-term dual antiplatelet treatment for stroke prevention. Stroke 44: 3623-4.

49. White H, Jamieson DG (2010) Review of the ESPRIT study: aspirin plus dipyridamole versus aspirin alone for prevention of vascular events after a noncardioembolic, mild-to-moderate ischemic stroke or transient ischemic attack. Postgraduate Medicine 122: 227-29.

50. Hong KS, Lee JS (2015) Statins in Acute Ischemic Stroke: A Systematic Review. J Stroke 17: 282-301.

51. Широков EA (2015) Review of the book: Fonyakin A.V. Geraskina L.A. Prevention of ischemic stroke. Guidelines for lipid-lowering therapy. Moscow: IMAPRESS 3: 72.

52. Bernhardt J, Dewey H, Thrift A, Collier J, Donnan G (2008) A very early rehabilitation trial for stroke (AVERT): phase II safety and feasibility. Stroke 39: 390-6. 53. Langhorne P, Stott D, Knight A, Bernhardt J, Barer D, et al. (2010) Very early rehabilitation or intensive telemetry after stroke: a pilot randomised trial. Cerebrovasc Dis 29: 352-60

54. Diserens K, Moreira T, Hirt L, Faouzi M, Grujic J, et al. (2012) Early mobilization out of bed after ischaemic stroke reduces severe complications but not cerebral blood flow: a randomized controlled pilot trial. Clin Rehabil 26: 451-59.

55. Indredavik B, Bakke F, Slordahl SA, Rokseth R, Haheim LL (1999) Treatment in a combined acute and rehabilitation stroke unit: which aspects are most important? Stroke 30: 917-23.

56. Cumming TB, Collier J, Thrift AG, Bernhardt J (2008) The effect of very early mobilisation after stroke on psychological well-being. J Rehabil Med 40: 609-14. 57. Sundseth A, Thommessen B, Rønning OM (2012) Outcome after mobilization within 24 hours of acute stroke: a randomized controlled trial. Stroke 43: 238994.

58. Bernhardt J, English C, Johnson L, Cumming TB (2015) Early mobilization after stroke: early adoption but limited evidence. Stroke 46: $1141-6$.

59. Hommel M (1996) Tissue Plasminogen Activator for Acute Ischemic Stroke. N Engl J Med 334: 1405-6.

60. Disorders T N I O N, Group R P S S. NINDS rt-PA Stroke Study Group (1995) Tissue plasminogen activator for acute ischemic stroke. New Engl J Med 333: 1581-8.

61. Hacke W, Kaste M, Fieschi C, Toni D, Lesaffre E, et al. (1995) Intravenous thrombolysis with recombinant tissue plasminogen activator for acute hemispheric stroke. The European Cooperative Acute Stroke Study (ECASS). JAMA 274: 1017-25.

62. Hacke W, Kaste M, Fieschi C, von Kummer R, Davalos A, et al. (1998) Randomised double-blind placebo-controlled trial of thrombolytic therapy with intravenous alteplase in acute ischaemic stroke (ECASS II). Second European-Australasian Acute Stroke Study Investigators. Lancet 352: $1245-51$.

63. Clark WM, Albers GW, Madden KP, Hamilton S (2000) The rt-PA (alteplase) 0-to 6-hour acute stroke trial, part A (A0267g): results of a double blind, placebocontrolled, multicenter study. Stroke 31: 811-816. 
64. Clark WM, Wissman S, Albers GW, Jhamandas JH, Madden KP, et al. (1999) Recombinant Tissue-Type Plasminogen Activator (Alteplase) for Ischemic Stroke 3 to 5 Hours After Symptom Onset: The ATLANTIS Study: A Randomized Controlled Trial. JAMA 282: 2019-26.

65. Hacke W, Donnan G, Fieschi C, Kaste M, von Kummer R, et al. (2004) Association of outcome with early stroke treatment: pooled analysis of ATLANTIS, ECASS and NINDS rt-PA stroke trials. Lancet 363: 768-74.

66. Fagan S, Morgenstern L, Pettita A, Ward RE, Tilley BC, et al. (1998) Cost-effectiveness of tissue plasminogen activator for acute ischemic stroke. Neurology 50: 883-890.

67. Hacke W, Kaste M, Bluhmki E, Brozman M, Dávalos A, et al. (2008) Thrombolysis with alteplase 3 to 4.5 hours after acute ischemic stroke. N Engl J Med 359:1317-29.

68. Davis SM, Donnan GA, Parsons MW, Levi C, Butcher KS, et al. (2008) Effects of alteplase beyond 3 h after stroke in the Echoplanar Imaging Thrombolytic Evaluation Trial (EPITHET): a placebo-controlled randomized trial. Lancet Neurol 7: 299-309.

69. Albers G W, Thijs V N, Wechsler L, Kemp S, Schlaug G, et al. (2006) Magnetic resonance imaging profiles predict clinical response to early reperfusion: the diffusion and perfusion imaging evaluation for understanding stroke evolution (DEFUSE) study. Ann Neurol 60: 508-17.

70. Ogata T, Christensen S, Nagakane Y, Ma H, Campbell BC, et al. (2013) The effects of alteplase 3 to 6 hours after stroke in the EPITHET-DEFUSE combined dataset: post hoc case-control study. Stroke 44: 87-93.

71. Arauz A, Phillips S, Gubitz G, Hankey GJ, Correia M, et al. (2012) The benefits and harms of intravenous thrombolysis with recombinant tissue plasminogen activator within $6 \mathrm{~h}$ of acute ischaemic stroke (the third international stroke trial [IST-3]): a randomised controlled trial. Lancet 379: $2352-63$.

72. IST-3 collaborative group (2013) Effect of thrombolysis with alteplase within $6 \mathrm{~h}$ of acute ischaemic stroke on long-term outcomes (the third International Stroke Trial [IST-3]): 18-month follow-up of a randomised controlled trial. Lancet Neurol 12: 768-76.

73. Lees K R, Bluhmki E, Von K R, Allen K, Mau J ,et al. (2010) Time to treatment with intravenous alteplase and outcome in stroke: an updated pooled analysis of ECASS, ATLANTIS, NINDS, and EPITHET trials. Lancet 375: 1695-703.

74. Lansberg M G, Bluhmki E, Thijs V N (2009) Efficacy and safety of tissue plasminogen activator 3 to 4.5 hours after acute ischemic stroke: a meta-analysis. Stroke 40: 2438-41.

75. ESO (2009) European Stroke Organisation guidelines for stroke management: Update January 2009.

76. National Stroke Foundation (2010) Clinical guidelines for stroke management 2010. Melboume Australia.

77. Minematsu K, Toyoda K, Hirano T, Kimura K, Kondo R, et al. (2013) Guidelines for the intravenous application of recombinant tissue-type plasminogen activator (alteplase), the second edition, October 2012: a guideline from the Japan Stroke Society. J Stroke Cerebrovasc 22: 571-600.

78. Genentech (2014) Activase (Alteplase).

79. Wardlaw JM, Murray V, Berge E, delZoppo GJ (2014) Thrombolysis for acute ischaemic stroke. Cochrane Database Syst Rev 29 : CD000213.

80. Emberson J, Lees KR, Lyden P, Blackwell L, Albers G, et al. (2014) Effect of treatment delay, age, and stroke severity on the effects of intravenous thrombolysis with alteplase for acute ischaemic stroke: a meta-analysis of individual patient data from randomised trials. Lancet 384:1929-35.

81. Lansberg MG, Albers GW, Wijman CA (2007) Symptomatic intracerebral hemorrhage following thrombolytic therapy for acute ischemic stroke: a review of the risk factors. Cerebrovasc Dis 24:1-10.

82. Flint AC, Gupta R, Smith WS, Kamel H, Faigeles BS, et al. (2014) The THRIVE score predicts symptomatic intracerebral hemorrhage after intravenous tP! administration in SITS-MOST. Int J Stroke 9:705-10.

83. Katzan IL, Hammer MD, Hixson ED, Furlan AJ, Abou-Chebl A, et al. (2004) Utilization of intravenous tissue plasminogen activator for acute ischemic stroke. Arch Neurol 61: 346-50.

84. Schenkel J, Weimar C, Knoll T, Haberl RL, Busse O, et al. (2003) R1-systemic thrombolysis in German stroke units-the experience from the German Stroke data bank. J Neurol 250:320-4.

85. California Acute Stroke Pilot Registry (CASPR) Investigators (2005) Prioritizing interventions to improve rates of thrombolysis for ischemic stroke. Neurology 64: 654-9.

86. Chapman SN, Mehndiratta P, Johansen MC, McMurry TL, Johnston KC, et al. (2014) Current perspectives on the use of intravenous recombinant tissue plasminogen activator (tPA) for treatment of acute ischemic stroke. Vasc Health Risk Manag 10: 75-87.

87. Ferrell AS, Britz GW (2013) Developments on the horizon in the treatment of neurovascular problems. SurgNeurolInt 4: S31-7.

88. Saqqur M, Uchino K, Demchuk A M, Akhtar N, Orouk FO, et al. (2007) Site of Arterial Occlusion Identified by Transcranial Doppler Predicts the Response to Intravenous Thrombolysis for Stroke. Stroke 38: 948-54.

89. Fuentes B, Masjuan J, Alonso d L M, Simal P, Egido J et al. (2012) Benefits of intravenous thrombolysis in acute ischemic stroke related to extra cranial internal carotid dissection. Dream or reality?. Int J Stroke 7:7-13.

90. Mishra NK, Lyden P, Grotta JC, Lees KR, Alexandrov A, et al. (2010) Thrombolysis is associated with consistent functional improvement across baseline stroke severity: a comparison of outcomes in patients from the Virtual International Stroke Trials Archive (VISTA). Stroke 41: 2612-7.

91. Riedel CH, Zimmermann P, Jensen-Kondering U, Stingele R, Deuschl G, et al. (2011) The importance of size: successful recanalization by intravenous thrombolysis in acute anterior stroke depends on thrombus length. Stroke 42: 1775-7.

92. Furlan AJ, Higashida R, Wechsler L, et al. (1999) PROACT II: Recombinant prourokinase (r-ProUK) in acute cerebral thromboembolism. Initial trial results the PROACT II investigators. Stroke 30: 234.

93. IMS II Trial Investigators (2007) The Interventional Management of Stroke (IMS) II Study. Stroke 38: 2127-35.

94. Lee M, Hong KS, Saver JL (2010) Efficacy of intra-arterial fibrinolysis for acute ischemic stroke: meta-analysis of randomized controlled trials. Stroke 41: 932-7. 95. Arnaout OM, Rahme RJ, El Ahmadieh TY, Aoun SG, Batjer HH, et al. (2012) Past, present, and future perspectives on the endovascular treatment of acute ischemic stroke. Tech Vasc Interv Radiol 15: 87-92.

96. Smith WS, Sung G, Starkman S, Saver JL, Kidwell CS, et al. (2005) Safety and efficacy of mechanical embolectomy in acute ischemic stroke: results of the MERCI trial. Stroke 36:1432-8.

97. Smith W S, Sung G, Saver J, Budzik R, Duckwiler G, et al. (2008) Mechanical thrombectomy for acute ischemic stroke: final results of the Multi MERCI trial. Stroke 39:1205-12.

98. Ruff J, Froehler MT (2013) Status of endovascular interventions to treat acute ischemic stroke. Curr Treat Options Neurol 15: 557-66. 
99. Penumbra Pivotal Stroke Trial Investigators (2009) The penumbra pivotal stroke trial: safety and effectiveness of a new generation of mechanical devices for clot removal in intracranial large vessel occlusive disease. Stroke 40:2761-8.

100. Rohde S, Bosel J, HackeW, Bendszus M (2012) Stent retriever technology: concept, application and initial results. J Neurointerv Surg 4: $455-8$.

101. Saver JL, Jahan R, Levy EI, Jovin TG, Baxter B, et al. (2012) Solitaire flow restoration device versus the Merci retriever in patients with acute ischaemic stroke (SWIFT): a randomised, parallel-group, non-inferiority trial. Lancet 380: 1241-9.

102. Nogueira RG, Lutsep HL, Gupta R, Jovin TG, Albers GW, et al. (2012) Trevo versus Merci retrievers for thrombectomyrevascularisation of large vessel occlusions in acute ischaemic stroke (TREVO 2): a randomised trial. Lancet 380: 1231-40.

103. Broderick JP, Palesch YY, Demchuk AM, Jovin TG, Silver FL, et al. (2013) Interventional Management of Stroke (IMS) III Investigators. Endovascular therapy after intravenous t-PA versus t-PA alone for stroke. N Engl J Med 368: 893-903.

104. Kidwell CS, Jahan R, Gornbein J, Alger JR, Nenov V, et al. (2013) A trial of imaging selection and endovascular treatment for ischemic stroke. N Engl J Med 368: $914-23$.

105. Ciccone A, Valvassori L, Nichelatti M, Sgoifo A, Sterzi R, et al. (2013) Endovascular treatment for acute ischemic stroke. N Engl J Med 368: $904-13$.

106. Yoshimura S, Shirakawa M, Uchida K, Tanaka Y, Shindo S (2014) Endovascular Treatment of Acute Ischemic Stroke: Honolulu Shock and Thereafter. J Stroke Cerebrovasc Dis 23: e295-8.

107. Asadi H, Dowling R, Yan B, Wong S, Mitchell P (2015) Advances in endovascular treatment of acute ischaemic stroke. Intern Med J 45: 798-805.

108. Holodinsky JK, Yu AY, Assis ZA, Menon BK, Demchuk AM, et al. (2016) History, Evolution, and Importance of Emergency Endovascular Treatment of Acute Ischemic Stroke. Curr Neurol Neurosci Rep 16: 42.

109. Berkhemer OA, Fransen PS, Beumer D, Yoo AJ, Schonewille WJ, et al. (2015) MR CLEAN Investigators.A randomized trial of intraarterial treatment for acute ischemic stroke. N Engl J Med 372:11-20.

110. Goyal M, Demchuk AM, Menon BK, Williams D, Bang OY, et al. (2015) ESCAPE Trial Investigators. Randomized assessment of rapid endovascular treatment of ischemic stroke. N Engl J Med 372:1019-30.

111. Campbell BC, Mitchell PJ, Kleinig TJ, Yassi N, Yan B, et al. (2015) Endovascular therapy for ischemic stroke with perfusion-imaging selection. N Engl J Med 372: 1009-18.

112. Saver JL, Goyal M, Bonafe A, Diener HC, Levy EI, et al. (2015) SWIFT PRIME Investigators. Stent-retriever thrombectomy after intravenous t-PA vs. t-PA alone in stroke. N Engl J Med 372:2285-95.

113. Jovin TG, Chamorro A, Cobo E, Carlos AM, Laura D, et al. (2015) Thrombectomy within 8 hours after symptom onset in ischemic stroke. N Engl J Med 372: 2296-306.

114. Mocco J, Zaidat O, Von Kummer R, Khatri P, Zaidat O, et al. (2015) Results of the THERAPY trial: A prospective, randomized trial to define the role of mechanical thrombectomy as adjunctive treatment to ivrtpa in acute ischemic stroke. Int J Stroke 10:10.

115. Bracard S, Guillemin F, Ducrocq X (2015) THRACE study: Intermediate analysis results. Int J Stroke 10:31.

116. Rodrigues FB, Neves JB, Caldeira D, Ferro JM, Costa J, et al. (2016) Endovascular treatment versus medical care alone for ischaemic stroke: systematic review and meta-analysis. BMJ 353:i1754.

117. Chen CJ, Ding D, Starke RM, Crowley RW, Liu KC, et al. (2015) Endovascular vs medical management of acute ischemic stroke. Neurology 85: 1980-90.

118. Yarbrough CK, Ong CJ, Beyer AB, Lipsey K, Derdeyn CP (2015) Endovascular Thrombectomy for Anterior Circulation Stroke: Systematic Review and MetaAnalysis. Stroke 46: 3177-83.

119. Badhiwala JH, Nassiri F, Alhazzani W, Spears J, Kulkarni AV, et al. (2015) Endovascular Thrombectomy for Acute Ischemic Stroke: A Meta-analysis. JAMA 314: 1832-43.

120. Mazighi M, Meseguer E, Labreuche J, Amarenco P (2012) Bridging therapy in acute ischemic stroke: a systematic review and meta-analysis. Stroke 43: 1302-8. 121. Hui FK, Yim J, Spiotta AM, Hussain MS, Toth G (2012) Intermediate catheter injections in closed segments during acute stroke intervention: a cautionary note. J Neurointerv Surg 4: e39.

122. Akins PT, Amar AP, Pakbaz RS, Fields JD , SWIFT Investigators (2014) Complications of endovascular treatment for acute stroke in the SWIFT trial with Solitaire and Merci devices. Am J Neuroradiol 35: 524 -8.

123. Liebig T, Gralla J, Schroth G (2015) Endovascular Treatment of Acute Stroke: Evolution and Selection of

Techniques and Instruments Based on Thrombus Imaging. Clin Neuroradiol 25: 299-306.

124. Powers WJ, Derdeyn CP, Biller J, Coffey CS, Hoh BL, et al. (2015) American Heart Association/American Stroke Association focused update of the 2013 guidelines for the early management of patients with acute ischemic stroke regarding endovascular treatment. Stroke $46: 3020$-35.

125. Wahlgren N, Moreira T, Michel P, , Steiner T, Jansen O, et al. (2016) Mechanical thrombectomy in acute ischemic stroke: Consensus statement by ESOKarolinska Stroke Update 2014/2015, supported by ESO, ESMINT, ESNR and EAN. Int JStroke 11: 134 -47.

126. Schonewille WJ, Wijman CA, Michel P, Weimar C, Mattle HP, et al. (2009) Treatment and outcomes of acute basilar artery occlusion in the basilar artery international cooperation study (BASICS): a prospective registry study. Lancet Neurol 8: 724-30.

127. Yeung JT, Matouk CC, Bulsara KR, Kevin NS (2015) Endovascular revascularization for basilar artery occlusion. IntervNeurol 3: $31-40$.

128. Gerber J, Puetz V, Bodechtel U, Kitzler H, von Kummer R, et al. (2016) Endovascular treatment of ischaemic stroke patients - New evidence and old challenges. Vasa 45: 267-74. 


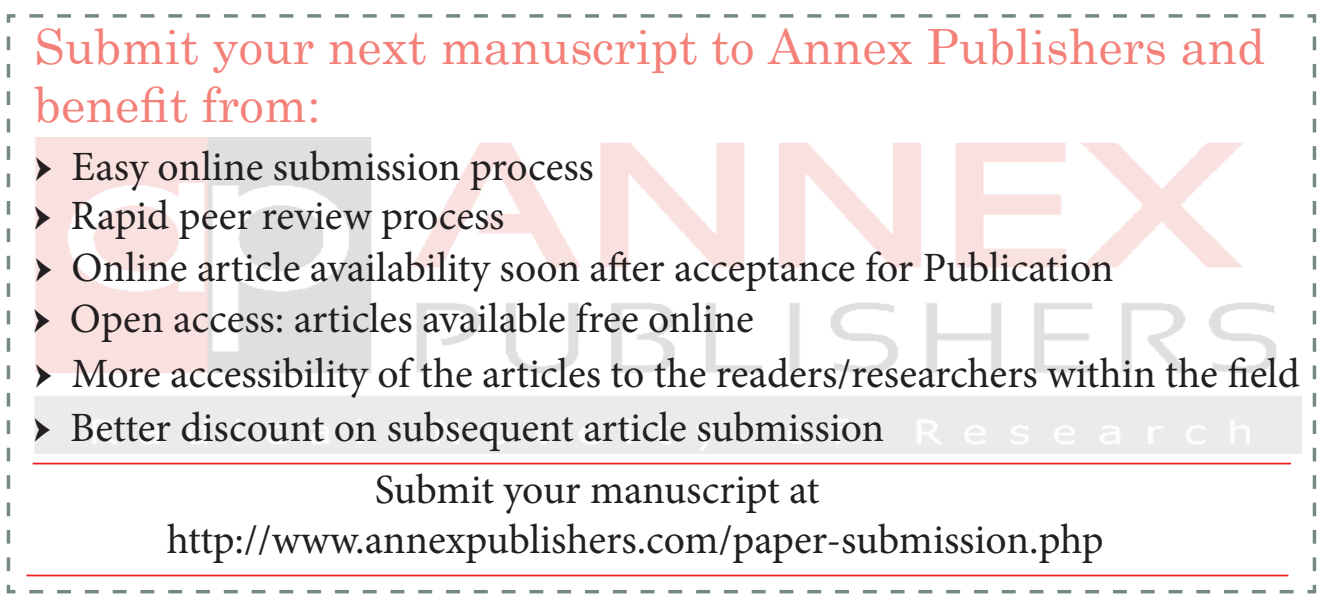

